\title{
Mirror image arrangement of the abdominal organs with a left-sided morphologically normal heart
}

\author{
LEONARD V SACKS, IAN R RIFKIN \\ From the Department of Internal Medicine, One Military Hospital, Voortrekkerhoogte, South Africa
}

SUMmaRY A twenty year old man is described who has a left-sided liver, a single right-sided spleen, an anomalous inferior vena cava with azygos continuation, and a morphologically normal left-sided heart. These findings emphasise the pitfalls in predicting cardiac abnormalities from other aberrations of anatomical situs.

Problems in the understanding and classification of abnormal body situs have tormented clinicians and anatomists for years. A basis for our current approach to this topic was proposed by Van Praagh et al some twenty years $a{ }^{1}$; in their scheme cardiac situs is analysed in terms of three developmental segments-the visceroatrial situs, the ventricular loop, and the conotruncus. Subsequent work has demonstrated the pitfalls in this approach. ${ }^{23}$ It is now clear that independent abnormalities of situs may affect the abdominal viscera, the bronchial arrangement, and the laterality of the atria. Bronchial situs may be solitus or inversus and there may be left or right isomeric configurations of the atria. ${ }^{24}$ Although disparity between the situs of these components is usually associated with important cardiac disease $^{5}$ this is not invariably so as the case below shows.

\section{Case report}

A 20 year old previously healthy white man presented to hospital with acute bronchitis. The clinical examination of his cardiovascular system revealed a normal heart with the apex beat located in the fifth left intercostal space in the midclavicular line. Some fullness of the internal jugular vein was noted on the right with a jugular venous pressure $3 \mathrm{~cm}$ above the sternal angle. Percussion of the chest

Requests for reprints to Dr Leonard V Sacks, 71 Tregoning Street, Linksfield, Johannesburg 2192, South Africa. demonstrated an unexpected absence of normal liver dullness on the right, but marked dullness below the sixth intercostal space on the left. The edge of the liver could only just be palpated below the left costal margin. The spleen was not felt. On auscultation of the lungs, rhonci were present in the right lower lobe which disappeared after one week of antibiotic treatment. A chest $x$ ray showed a normal cardiac contour with a distended azygos vein measuring $2.1 \mathrm{~cm}$ in diameter on tomography that was suggestive of a venous anomaly (fig 1 ). ${ }^{6}$ A stomach bub-

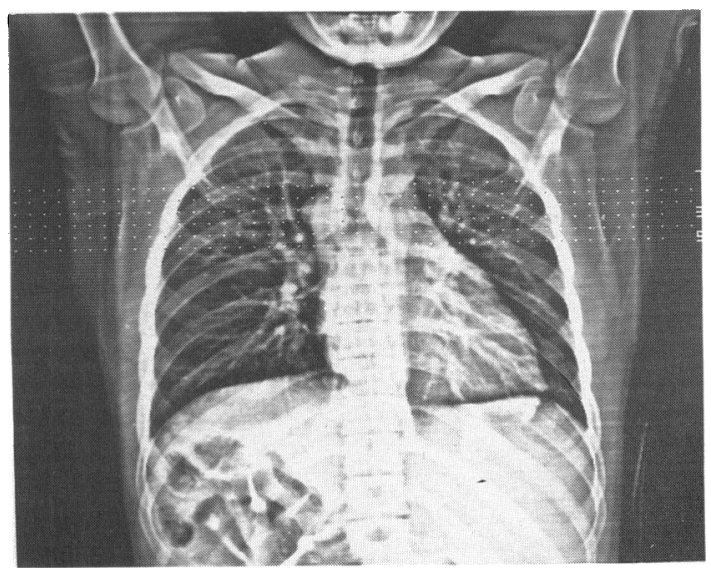

Fig $1 X$ ray of chest and upper abdomen showing the left-sided liver and left-sided heart. 
ble was apparent below the right hemidiaphragm and there was a diffuse opacity below the left. The right hemidiaphragm occupied a normal position, $1 \mathrm{~cm}$ higher than the left.

The electrocardiogram showed a $P$ wave of normal configuration with an axis of $60^{\circ}$. Episodes of nodal rhythm were present alternating with a normal sinus arrhythmia, during which the P-R interval was constant at $0.12 \mathrm{~s}$. The QRS complex was normal.

Echocardiography was also ostensibly normal with a normal appearance of the atria and atrioventricular valves. Interatrial and interventricular septa were intact. Attempts to demonstrate the morphology of the atrial appendages were not successful and the position of the pulmonary veins could not be reliably ascertained. Because of the distended azygos vein angiography of the inferior vena cava was performed. This showed an interruption of the inferior vena cava at the level of $\mathrm{Ll}$ with azygos continuation. The large distended azygos vein was shown to drain into a normal superior vena cava and a normal right atrium (fig 2). No drainage of the systemic venous system into the left atrium was evident. A penetrated $x$ ray film of the chest showed a

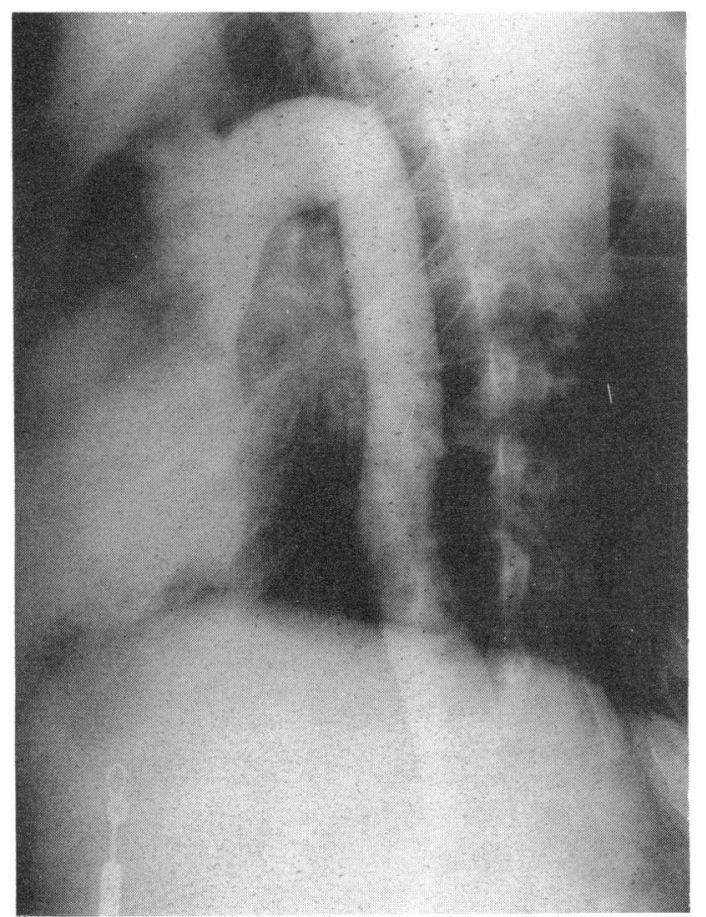

Fig 2 Angiogram of the inferior vena cava showing the large distended azygos vein draining into a normal superior vena cava and right atrium. normal solitus configuration of the tracheobronchial tree with a ratio between left and right main bronchial lengths of 1.8 that militated against the possibility of bronchial isomerism. ${ }^{4} \mathrm{~A}$ technetium scan of the abdomen demonstrated a left-sided liver and a single right-sided spleen. These findings point to the diagnosis of a mirror image configuration of the abdominal viscera, azygos continuation of the inferior vena cava, a normal situs solitus tracheobronchial tree, and a morphologically normal leftsided heart.

\section{Discussion}

The complexity of abnormalities in body situs necessitates a thorough investigation of several components, in particular atrial, tracheobronchial, and abdominal situs. Atrial situs has been regarded as pivotal to the understanding of cardiac situs. ${ }^{2}$ Ideally its determination relies on demonstrating the anatomy of the atrial appendages. ${ }^{3}$ Where this is not possible reasonable conclusions may be drawn from the nature of venous drainage to the heart, the state of the interatrial septum, the presence and location of the sinoatrial node, as well as the configuration of the tracheobronchial tree. ${ }^{78}$ Although we were unable to demonstrate the morphology of the atrial appendages in our case, the bulk of evidence points to a normal laterality of this patient's atria. The systemic venous drainage to the right atrium exclusively, the absence of any clinical suggestion of abnormal pulmonary venous drainage, the intact interatrial septum, and the normal sinoatrial node and atrioventricular valves support this contention. This assertion is supported by the solitus configuration of the tracheobronchial tree. ${ }^{7}$ Although the association between azygos continuation of the inferior vena cava and left atrial isomerism is well recognised ${ }^{27}$ it seems not to operate in this case. Our case clearly demonstrates that the position of the abdominal viscera may be misleading in predicting cardiac morphology and laterality.

Since most of the data on abnormalities of situs have been obtained either from postmortem studies or from patients presenting with important cardiac dysfunction, the rarity of the abnormality we have described may be the result of bias in case selection. Moreover, such cases are unlikely to come to medical attention, firstly because they are symptom free and secondly because of the paucity of clinical signs pointing to this anatomical aberration. The use of contemporary imaging techniques including echocardiography and radioisotope scanning is likely to lead to the discovery of more cases of abnormal situs by the clinician rather than the anatomist. 


\section{References}

1 Van Praagh R, Van Praagh S, Vlad P, Keith JD. Anatomic types of congenital dextrocardia. Am J Cardiol 1964;13:510-31.

2 Macartney FJ, Zuberbuhler JR, Anderson RH. Morphological considerations pertaining to recognition of atrial isomerism. Consequences for segmential chamber localisation. Br Heart J 1980;44:657-67.

3 Caruso G, Becker AE. How to determine atrial situs? Considerations initiated by 3 cases of absent spleen with a discordant anatomy between bronchi and atria. Br Heart J 1979;41:559-67.

4 Deanfield JE, Leanage R, Stroobant J, Chrispin AR, Taylor JFN, Macartney FJ. Use of high kilovoltage filtered beam radiographs for detection of bronchial situs in infants and young children. Br Heart $J$ 1980;44:577-83.

5 Baron MG. Radiological and angiographic examination of the heart. In: Braunwald E, ed. Heart disease. Philadelphia: WB Saunders, 1980:173.

6 Anderson RC, Adams P Jr, Burke B. Anomalous inferior vena cava with azygos continuation (infra hepatic interruption of the inferior vena cava). $J$ Pediatr 1961;59:370-83.

7 Sapire DW, Ho SY, Anderson RH, Rigby ML. Diagnosis and significance of atrial isomerism. Am J Cardiol 1986;58:342-6.

8 Huhta JC, Smallhorn JF, Marcartney FJ. Two dimensional echocardiographic diagnosis of situs. Br Heart J 1982;48:97-108. 